\title{
Paleofire workshop
}

\author{
Venice, Italy, 21-23 June 2012
}

\section{Natalie Kehrwald ${ }^{1}$, C. Barbante ${ }^{1,2}$, C. Whitlock and V. Brovkin ${ }^{4}$}

'Department of Environmental Science, Informatics and Statistics, University of Venice, Italy; kehrwald@unive.it ${ }^{2}$ Institute for the Dynamics of Environmental Processes, Consiglio Nazionale delle Ricerche, Venice, Italy; ${ }^{3}$ Department of Earth Sciences, Montana State University, Montana, USA; ${ }^{M}$ Max Planck Institute for Meteorology, Hamburg, Germany

F ires are an integral aspect of the Earth System, affecting climate through the release of aerosols and greenhouse gases, altering natural vegetation patterns and land carbon storage, and transforming land use. Charcoal, ice core, and modeling communities have been addressing climate and fire interactions from different perspectives. Each community has historically used separate approaches. This difference can partly be attributed to proxy availability or the necessity to produce data for various audiences including fire control and time-slice climate reconstructions. This workshop aimed at facilitating interactions between the three communities. The key workshop goals were to:

(1) Determine the status of existing data from each group and analyze the strengths and weaknesses of each data type,

(2) Identify how we can present our data so that each community (charcoal, ice core and modeling) can best use the results to further improve understanding of fire-related processes,

(3) Highlight ways to integrate the data of each group.

The charcoal community has compiled the Global Charcoal Database (GCD; www.ncdc.noaa.gov/paleo/impd/gcd. html) to create regional reconstructions and analyses of fire activity during specific time slices. Charcoal records can offer detailed local information that is often used to produce fire danger indices or to aid in land management. There are extensive charcoal records covering North America, the Mediterranean, and Australia, while other areas such as central Russia and Africa have sparse records, due in part to the lack of lakes with suitable sediments. The growing collaboration among researchers who study the impacts of fire and climate over regional scales will allow for the inclusion of charcoal records from larger lakes, permitting a more detailed understanding of fire history, particularly in data-sparse regions.

Ice core reconstructions of past fire activity complement charcoal studies because multiple parameters can be used to distinguish between fires from biomass

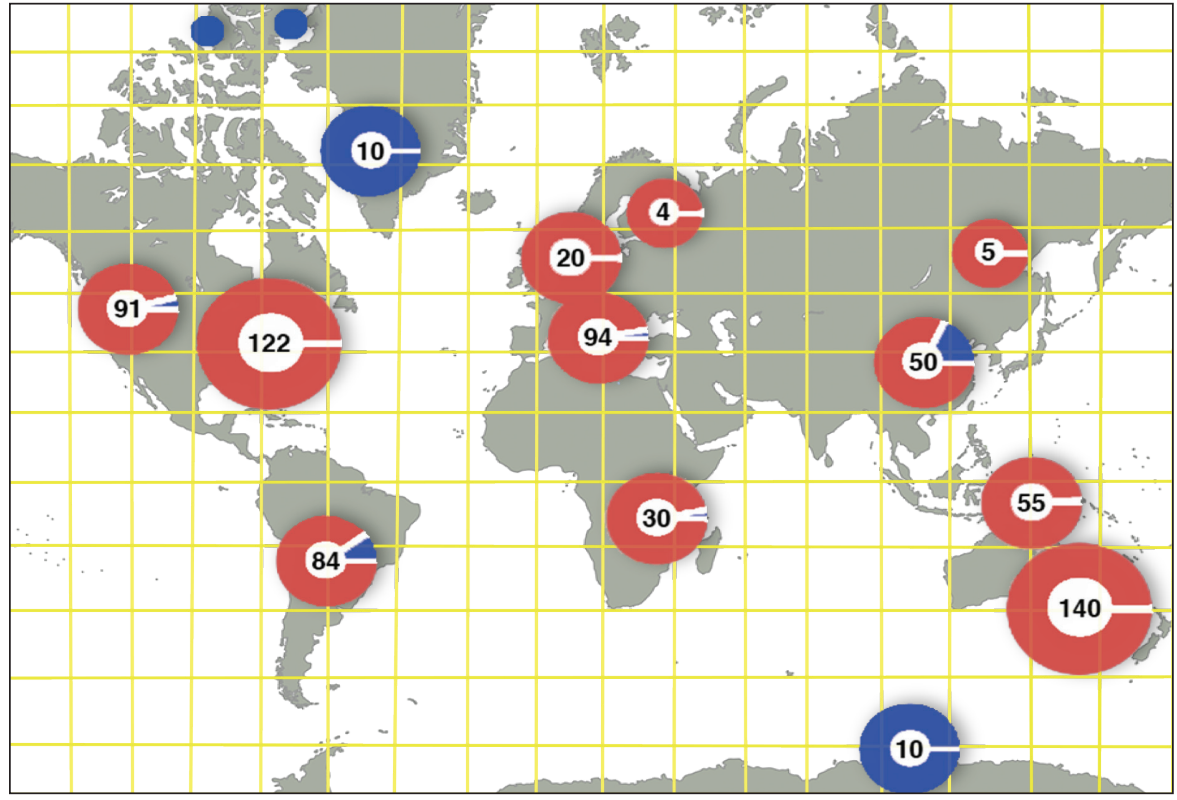

Figure 1: The Global Charcoal Database core locations (red, Daniau et al. 2012) and ice core sites to bedrock (blue) by geographic region. The numbers are the totals of both proxy records per location. The grid is a schematic representation of the ability of climate models to integrate multiple parameters over wide spatial scales and across areas where proxy data do not exist.

fuel sources and those from fossil fuel emissions. Biomass burning tracers in ice cores with atmospheric residence times ranging from days to weeks include black carbon, elemental carbon, particulate organic carbon, monosaccharide anhydrides such as levoglucosan, organic acids, ammonium, nitrate and potassium, polycyclic aromatic hydrocarbons, and charcoal. Markers with an atmospheric residence time ranging from months to years tend to be hemispheric to global in scope. These ice core markers include carbon monoxide, $\delta^{18} \mathrm{O}$ of carbon monoxide, $\delta^{13} \mathrm{C}$ of methane, and non-methane hydrocarbons. The variety of tracers in ice cores allows the researcher to select markers based on a particular research goal, such as the production of high-resolution measurements or the unambiguous determination of past vegetation fires. Such reconstructions are steadily increasing, as new techniques demand smaller sample sizes. However, the multitude of ice core proxies and the novelty of many of these techniques currently create challenges for standardizing records into a compilation similar to the GCD.

Fire models are able to simulate firerelated processes at multiple spatial and temporal scales. Applied to past climates, the current generation of Earth System models is capable of providing regional reconstructions of changes in fuel load and moisture, biomass and burned area, and charcoal deposition. Atmospheric transport models are routinely used to estimate backward trajectories of aerosol particles and trace gases and to identify source and sink regions. Future work includes simulating the transport of tropospheric ozone or tracers such as organic biomarkers and black carbon, as well as a detailed comparison of simulated changes in burned area with charcoal and ice core proxies.

Workshop participants agreed that future research directions should focus on calibration studies for individual proxies, as well as between proxies. The workshop provided an opportunity to begin compiling and using an array of proxy data and model output to address major research questions in interdisciplinary fire science.

\section{Reference}

Daniau A-L et al. (2012) Global Biogeochemical Cycles 26, doi:10.1029/2011GB004249 